\title{
A memória como critério de aferição de qualidade no ciberjornalismo: alguns apontamentos*
}

\section{RESUMO}

A consolidação da Internet como suporte para a atividade jornalística, em anos recentes, trouxe consigo a necessidade de avaliação de Qualidade dos produtos disponibilizados na Web.Transpor para a Internet critérios de avaliação, metodologias e ferramentas utilizadas na análise de Qualidade de produtos impressos deixa de fora especificidades importantes dos veículos produzidos online. Por outro lado, as ferramentas já existentes para a avaliação de Websites são de caráter genérico, produzindo resultados aos quais escapam características que são próprias do fazer jornalístico. Este artigo explora algumas dessas dificuldades e utiliza o exemplo da Memória estendida para indicar alguns dos desafios colocados para os analistas de produtos jornalísticos produzidos para redes telemáticas de alta velocidade.

\section{PALAVRAS-CHAVE \\ jornalismo \\ jornalismo na Internet \\ qualidade}

\section{ABSTRACT}

The consolidation of cyberjournalism as a new form of journalistic production in recent years brought about the need for quality evaluation of newspapers and magazines produced for the Web. The use of the same concepts and analytic tools developed for the traditional press in the evaluation of cyberjournalism leads to the undervaluation of specific characteristics of journalistic products designed for the new medium. On the other hand, analytic tools used for Website evaluation are generally too generic and ill adapted for the specificities of cyberjournalism. In this article we explore some of the difficulties involved in online journalism quality evaluation. The difficulties in analyzing memory in cyberjournalism is used to indicate some of the challenges posed for the webnewspaper analyst.

\section{KEY WORDS}

media

journalism

history
Na língua inglesa é corrente o uso das expressões Quality Press e Popular Press para classificar, respectivamente, os "jornais de elite" e os "jornais populares" (em geral de formato tablóide). A proximidade semântica entre "Qualidade" e "Elite", por outro lado, remonta ao período 1780/1845 (Hobsbawn, 1962), quando o vocábulo "Elite", anteriormente restrito ao mundo dos negócios, como designação de mercadorias de "tipo superior", generaliza-se a adquire a conotação social que hoje o caracteriza (elite econômica, social, intelectual, etc) ${ }^{1}$.

Avaliar a Qualidade de produtos jornalísticos de maneira sistemática e controlada é um esforço que se inscreve no movimento geral de preocupação com Qualidade, especialmente na área Administração, ao redor dos anos 30 do século passado, ganhando grande impulso logo após a Segunda Guerra Mundial, principalmente nos Estados Unidos e Japão, nos esforços de reconstrução pós-guerra (Jimenez e Ortiz-Repiso, 2007).

Mais recentemente, padrões internacionais passaram a ter aceitação e vigência, através de organismos como a International Standard Organisation (ISO), representada no Brasil pela ABNT (Associação Brasileira de Normas Técnicas). No entanto, quando buscamos definições em termos mais claros e diretos, deparamo-nos com fórmulas que parecem colocar mais problemas que resolvê-los, como é o caso da Norma ISO 8402, que estabelece:

A Qualidade é o conjunto de propriedades e características de um produto ou serviço que lhe confere sua aptidão para satisfazer necessidades expressas ou implícitas (Apud Jiménez \& Ortiz Repiso, 2007p, 53).

Explica, ou complica? Estabelece patamares claros para julgamento, ou simplesmente abre totalmente a questão, declarando o primado da subjetividade dos usuários? Ou seria o caso de tomarmos a idéia de "necessidades expressas ou implícitas" como "padrões médios" de exigência historicamente determinados para cada produto e cada realidade nacional/regional?

Nosso esforço neste breve artigo será levantar algumas dificuldades que a tarefa de avaliar Qualidade de produtos Ciberjornalísticos está enfrentando (ou a ponto de enfrentar), em função da consolidação da prática jornalística nas redes telemáticas de alta velocidade (especialmente a Internet) e seus desdobramentos. A Memória, como uma característica já presente em alguma medida em suportes jornalísticos tradicionais (imprensa, rádio, TV), porém tremendamente potencializada na Web, será usada como exemplo para indicar algumas

\section{Marcos Palacios}

Professo de Jornalismo da UFBA/BA/BR 
das novidades e inúmeros desafios colocados para o analista do Ciberjornalismo.

\section{$\mathbf{0}$ que se está medindo?}

Segundo o Dicionário Michaelis da Língua Portuguesa, o vocábulo Qualidade, substantivo feminino, do latim qualitate, tem pelo menos quatro conotações que interessam diretamente a esta nossa discussão: " 1 Atributo, condição natural, propriedade pela qual algo ou alguém se individualiza, distinguindo-se dos demais; maneira de ser, essência, natureza. 2 Excelência, virtude, talento. 3 Grau de perfeição, de precisão, de conformidade a um certo padrão. 4 Filos Conjunto de aspectos sensíveis da percepção resultantes de uma síntese efetuada pelo espírito. 5 Filos Acidente que modifica a substância, sem lhe alterar a essência".

Além disso, em termos filosóficos, poderíamos também fazer a distinção entre qualidades primárias (aquelas sem as quais os corpos não podem ser concebidos: extensão e impenetrabilidade) e secundárias (as que podem ser eliminadas por abstração sem suprimir a idéia de corpo: cor, sabor, cheiro etc.).

Na primeira acepção das cinco mencionadas acima, há referência tanto à individualização, quanto à distinção em relação a congêneres em um grupo; na segunda e terceira, sobressaem atributos de excelência e de conformidade a certo padrão mínimo. A quarta acepção, de caráter filosófico, reforça a idéia de que Qualidade é algo que resulta de uma síntese estabelecida pelo espírito (i.e. pela percepção individual) quanto a um conjunto de características ou aspectos sensíveis presentes na substância ou situação, sendo, em última instância, sempre uma avaliação de tipo subjetivo. É uma definição deste teor - com o complicador da variação cultural - que prevalece na Wikipedia, no verbete Qualidade:

Qualidade é um conceito subjetivo que está relacionado diretamente às percepções de cada indivíduo. Diversos fatores como cultura, modelos mentais, tipo de produto ou serviço prestado, necessidades e expectativas influenciam diretamente nesta definição (Wikipedia, acesso em 25/07/08).

O que parece emergir como mais ou menos consensual em tais discussões é que Qualidade seria algo que resulta de uma sintese estabelecida pela percepção individual (subjetiva) quanto a um conjunto de características ou aspectos sensiveis presentes na substância ou situação. Assim, faz sentido que, metodologicamente, o esforço dos analistas que se propuseram, historicamente, a criar modelos e instrumentos para a aferição de qualidade dos mais diversos produtos e serviços tenha sido, justamente, "objetivar" a questão. Ou seja, partindo-se da premissa de que a noção e a percepção do que seja Qualidade varia de indivíduo para indivíduo, trata-se de propor formas mais ou menos "consensuais" ou "intersubjetivas" de mensuração - sempre é claro de forma provisória e ad hoc - para um conjunto de "características e aspectos sensíveis" dos produtos a serem analisados. Está posta em causa, portanto, a questão da subjetividade e da busca de mecanismos para senão eliminá-la, pelo menos reduzi-la.

Operacionalizada a mensuração, através das categorias selecionadas, tem-se como meta o estabelecimento de um ranking dos produtos observados, através dos instrumentos criados e utilizados. Ou seja, torna-se possível construir uma escala de posições relativas ao conjunto de características observadas, definindo-se pontos extremos ("o melhor e o pior") no grupo de produtos analisados.

\section{Com que régua medir?}

É claro, portanto, que a seleção do que constitui o conjunto de atributos a serem observados é crucial. Antes de se propor qualquer tipo de escala ou variação (como escalas de Likert, por exemplo), a tarefa que se impõe, inicialmente, é justamente decidir que "características e aspectos sensíveis" entram ou ficam de fora na construção do conjunto de atributos a serem medidos.

Em alguns casos o que está sendo medido (Qualidade) não é sequer definido ou colocado em discussão, mas tomado como algo dado a priori. Daniel Sutter (2004), por exemplo, parte da premissa que "a busca do lucro pode colidir com a produção de jornalismo de qualida$\mathrm{de}^{\prime \prime}$, mas em nenhuma parte de seu artigo encontramos uma definição de Qualidade, apesar de que, ao longo do paper, esteja implícita a idéia de que os jornalistas "sabem" o que seja Qualidade em um produto jornalístico. No artigo, Sutter busca correlacionar a atribuição de Prêmios Pulitzer (um reconhecimento de Qualidade) com a circulação de veículos premiados.

Ou seja, Sutter utiliza-se de uma "régua" já existente para fazer seu próprio estudo de correlação entre Qualidade e circulação. No entanto, se formos investigar que critérios compõem a "régua do Pulitzer", vamos nos deparar com a surpreendente afirmação que "não há critérios pré-estabelecidos para julgar os Prêmios Pulitzer. Compete aos jurados indicados e à Pulitzer Prize Board estabelecer exatamente o que torna um trabalho "diferenciado" ("distinguished")"2.

Um dos autores tradicionalmente apontado como pioneiro no campo da avaliação de produtos jornalísticos, John Merril, em seu livro The Elite Press, de 1968, no qual produz um ranking dos maiores jornais do mundo, chega a afirmar textualmente que "como os jornais são lidos e julgados por diferentes pessoas com diferentes critérios, os pesquisadores não devem ter receio de avaliar a Qualidade dos jornais usando seus próprios critérios subjetivos" (Apud Meyer \& Kim, 2003). Nesse estudo de 1968, Merril estabelece os seguintes critérios para avaliação de Qualidade:

1. Independência; estabilidade financeira; integridade; preocupação social; boa escrita e boa edição;

2. Opiniões fortes e ênfase interpretativa; consciência do 
mundo; rejeição do sensacionalismo e "make-up";

3. Ênfase em política, relações internacionais, economia, questões de bem estar social, assuntos culturais e ciência;

4. Preocupação com a aquisição, manutenção e desenvolvimento de uma equipe profissional ampla, inteligente, bem educada, articulada e tecnicamente proficiente;

5. Determinação de servir e ajudar a expandir um conjunto de leitores bem educado, inteligente tanto no âmbito doméstico quanto no exterior; desejo de demandar e influenciar líderes de opinião em toda a parte (Merril, 1968). ${ }^{3}$

Com o passar do tempo, através de críticas e re-elaborações, as categorias e critérios de análise começaram a se multiplicar e sofisticar. Uma primeira diferenciação, ocorre em um segundo trabalho de John Merril, em associação com Lowenstein, em 1971, no qual é estabelecida uma diferenciação entre critérios "internos" (relacionados ao próprio jornal) e "externos" (relacionados à audiência) para avaliação de Qualidade. Outros parâmetros de classificação dos critérios foram propostos e utilizados, a partir de então, por vários autores (Ghiglione, 1973; Stone, 1981; Gladney, 1990).

Em 1977, no início do Newspaper Readership Project ${ }^{4}$, Leo Bogart estava trabalhando com 23 critérios "objetivos" do tipo: quantidade total de material não publicitário publicado; relação entre material produzido na redação x material de agências; número de editoriais por edição do jornal; relação notícias $x$ material interpretativo; número e diversidade de colunistas, etc, etc. No entanto, o próprio Bogart assinalava que sete critérios subjetivos para a análise Qualidade permaneciam: precisão, imparcialidade, dimensão investigativa, qualificação da equipe especializada, individualidade de caráter, caráter cívico e estilo literário.

O problema é que tais critérios dificilmente podem ser aplicados quando se trata de estudos de larga escala, envolvendo muitos jornais (Bogart,1989, 2004). Ou seja, a despeito do caráter declaradamente positivista e quantitativista da abordagem de Bogart ${ }^{5}$ e dos acadêmicos norte-americanos, de modo geral, ele reconhece que, no "fundo do tacho", permanecem alguns elementos que não podem ser reduzidos a uma escala numérica. Para colocar a questão de forma quase circular: os estudos de Qualidade envolvem necessariamente aspectos qualitativos que não são "objetiváveis" em escalas numéricas, o que dificulta sobremaneira a realização de pesquisas com corpora de grandes dimensões.

Estudos posteriores partem dos critérios estabelecidos por Bogart e produzem subconjuntos menores para análises mais rápidas, como no caso de Lacy \& Fico (1990), que selecionaram os seguintes critérios: relação entre material produzido na redação $x$ material de agências; relação notícias x material interpretativo; alto volu- me de ilustrações por texto; dimensão média das matérias com chamadas na primeira página; quantidade total de material não publicitário; número de agências de notícias utilizadas; alta relação entre conteúdo editorial x material publicitário.

\section{Memória e Qualidade}

Mas talvez seja na quinta acepção de Qualidade das anteriormente apresentadas ("Acidente que modifica a substância, sem lhe alterar a essência") que nos aproximemos de um ponto de partida conveniente para nossos apontamentos quanto à Memória enquanto elemento de aferição de Qualidade no Ciberjornalismo. A Memória seria, em uma definição preliminar, um "aspecto ou característica" que, sem afetar a "essência" do jornalismo, nele introduz uma modificação perceptível ao espírito do observador. Tal "modificação", que estaria classificada como uma "qualidade secundária", conforme já vimos nos parágrafos acima, é certamente algo para se contemplar, quando o que está em causa é a mensuração diferencial de Qualidade nos produtos Ciberjornalísticos.

Se aceitarmos a noção de que "Qualidade é uma síntese a partir de um conjunto de características percebidas pelo espírito" (acepção 4), a Memória apresenta-se e soma-se como elemento novo e necessário ao quadro de atributos a serem examinados, em qualquer tentativa de se estabelecer padrões e rankings de Qualidade para as publicações online. Elemento novo porque ausente dos conjuntos de atributos tradicionalmente elencados como constituindo marcos de referência para avaliação de Qualidade em produtos jornalísticos disponíveis em outros suportes (impresso, rádio, TV); elemento recente, por estar diretamente associado à difusão e generalização do uso das bases de dados como característica do ciberjornalismo na fase das conexões rápidas (Machado, 2001, 2004; Barbosa, 2004, 2008a, 2008b; Fidalgo, 2004); elemento necessário por apresentar-se como um fator de ruptura no conjunto de características específicas do jornalismo produzido em redes digitais, uma vez que a Memória no novo suporte vai apresentar-se como "múltipla, instantânea e cumulativa" (Palacios, 2004; Canavilhas, 2004; Mielniczuk, \&. Barbosa, 2005; Silva Junior, 2006) e, portanto, extremamente potencializada com relação à sua expressão em suportes jornalísticos anteriores.

Essa Memória potencializada é um exemplo claro de uma característica (dentre várias) que marca especificidades do Ciberjornalismo e ilustra como a simples transposição e uso de instrumentos utilizados para análises em outros suportes se mostram insuficientes quando nos propomos a tarefa de avaliar e comparar veículos jornalísticos disponibilizados em redes telemáticas de alta velocidade.

As perguntas norteadoras desta incursão exploratória podem ser estabelecidas da seguinte forma:

a) que lugar a Memória vinha ocupando nos modelos propostos para avaliação da Qualidade de produtos 
jornalísticos anteriores à Web?

b) que posição passou a ocupar em exercícios de avaliação de Qualidade de produtos jornalísticos produzidos para a Web?

\section{A Memória antes da Web \\ Recorrer a material de arquivo e, portanto, à Memória é, evidentemente, uma prática que pré-data a Web e que sempre teve seu lugar, em maior ou menor escala, no processo de produção de informação jornalística:}

Os jornais impressos, desde longa data, mantêm arquivos físicos das suas edições passadas, abertos à consulta do público e utilizados por seus editores e jornalistas no processo de produção de informação noticiosa. No jornalismo impresso moderno foi sempre comum a publicação de pesquisas, baseadas em informação de arquivo, que complementam, ampliam ou ilustram o material noticioso corrente. $\mathrm{O}$ mesmo ocorre com relação às emissoras de rádio e TV, que mantém arquivos sonoros e de imagem, eventualmente utilizados na produção de material noticioso de caráter jornalístico ou documental (Palacios, 2004).

Chama a atenção, no entanto, que tal recurso não apareça elencado dentre os critérios "objetivos" criados por Merril (1968) ou Bogart (1977) e que serviram de base para os estudos de Qualidade na literatura norte-americana sobre o assunto, nos últimos 30 ou 40 anos. Bogart chega até a listar a presença de coluna de astrologia e o número de tiras de quadrinhos (comic strips) dentre os 23 critérios a serem medidos, porém nada encontramos que, mesmo remotamente, faça referência ao uso de arquivos ou à presença de recuperação de Memória nos textos jornalísticos.

Em trabalho apresentado em 2003, Meyer e Kim buscam uma nova síntese de indicadores a serem investigados na mensuração de Qualidade em jornais. Partindo da experiência acumulada e procedendo a uma revisão bibliográfica a partir dos estudos pioneiros de Merril (1968) e Bogart (1977), os autores selecionam e adaptam 15 dos indicadores originais de Bogart. A nova listagem de indicadores, proposta por Meyer e Kim, está organizada em torno de cinco fatores, a saber:

1. Facilidade de acesso;

2. Localismo;

3. Vigor Editorial;

4. Quantidade de Notícias;

5. Interpretação.

Na rubrica Interpretação vamos encontrar o que pode ser considerado uma referência ao uso de material de Memória, sobre a denominação de "backgrounders" para as notícias publicadas. No entanto, ainda desta vez a ênfase não se mostra suficiente para que a Memória seja avaliada como um critério específico, uma vez que o uso de "backgrounders" aparece em uma mesma questão, juntamente com "interpretations": "Alta ocorrência de interpretações de notícias e backgrounders para notícias simples ${ }^{\prime \prime} .6$

\section{Um problema que se coloca desde sempre com relação à avaliação da Qualidade em produtos jornalísticos na Web é o fato de que o instrumental disponível, tanto teórico quanto empírico tem sido, em sua grande maioria, criado e formatado para a análise de sites em geral, e não para 0 jornalismo em particular.}

Uma listagem de itens compilada pela Henry W. Gardy School of Journalism (University of Georgia) e apresentada como contendo os itens "linhas básicas usadas atualmente na publicação de jornais e revistas de qualidade", tampouco faz qualquer menção ao uso da Memória como atributo a ser mensurado na avaliação de uma publicação jornalística.

\footnotetext{
A Memória depois da Web

Longe de termos pretensão de exaustividade, a breve resenha bibliográfica que segue tem por objetivo ressaltar a lacuna representada pelo critério Memória, dentre aqueles usualmente elencados nas pesquisas voltadas para aferição de Qualidade nos produtos jornalísticos online.

Como enfatizamos em nosso trabalho de 2004, no jornalismo praticado na Internet:
}

Da mesma forma que a "quebra dos limites físicos" na Web possibilita a utilização de um espaço praticamente ilimitado para disponibilização de material noticioso, sob os mais variados formatos (multi)mediáticos, abre-se a possibilidade de disponibilização online de toda informação anteriormente produzida e armazenada, através da criação 
de arquivos digitais, com sistemas sofisticados de indexação e recuperação da informação (Palacios, 2004).

\section{Como conseqüência assinalávamos:}

(...) Que na Web, a conjugação de Memória com Instantaneidade, Hipertextualidade e Interatividade, bem como a inexistência de limitações de armazenamento de informação, potencializam de tal forma a Memória que é legítimo afirmar-se que temos nessa combinação de características e circunstâncias uma Ruptura com relação aos suportes mediáticos anteriores (Palacios, op cit).

Melinda McAdams (1995), em seu artigo sobre a construção da versão online do Washington Post, já assinalava a importância dos arquivos como agregação de valor e modelo de negócio (no caso cobrança para consultas a artigos anteriores a 1986), chamando atenção para a entusiástica respostas dos leitores quanto a colocação online dos arquivos e suas reclamações quanto à cobrança de acesso.

À medida que avançaram os recursos técnicos disponíveis para a produção do jornalismo na Web e, acima de tudo, na medida que os arquivos tornavam-se cada vez mais operacionais, em função da conjugação da web com as Bases de Dados (Machado, 2001, 2004; Barbosa, 2004, 2008a, 2008b; Fidalgo, 2004; ), a Memória passou a ser crescentemente incorporada ao fazer jornalístico na Web, seja como recurso de contextualização/ampliação do material noticioso diário, seja em "especiais" e reportagens em profundidade (Ribas, 2008).

Um problema que se coloca desde sempre com relação à avaliação da Qualidade em produtos jornalísticos na Web é o fato de que o instrumental disponível, tanto teórico quanto empírico (questionários, fichas de avaliação, etc) tem sido, em sua grande maioria, criado e formatado para a análise de sites em geral, e não para o jornalismo em particular ${ }^{7}$. Tal situação é claramente discernível, por exemplo, quando examinamos os modelos de análise heurística de Nielsen e daqueles que têm Nielsen como ponto de partida para proposição de formas de avaliação (Nielsen, 1999, 2001, 2004). Isso é inclusive verdade para o modelo de Lluis Codina, que vem servindo de base para as pesquisa em andamento no âmbito do Convênio de Colaboração Brasil-Espanha para o estudo dos Cibermeios (CAPES/DGU 140/07), e que serviram de ponto de partida para as presentes reflexões, como veremos adiante.

No panorama brasileiro, um trabalho de Carrato (2001), voltado para a avaliação da imprensa de Minas Gerais, basicamente compara versões online e impressas de jornais mineiros, sem qualquer menção ao uso de arquivos como fator diferencial. David (2004) apresenta uma reflexão sobre o uso ampliado da Memória no jornalismo online, que merece atenção pelos diversos pon- tos que levanta para uma possível incorporação da Memória como critério diferencial na avaliação de Qualidade, porém não são propostos instrumentos específicos para sua mensuração. Galarça (2005) em sua pesquisa sobre a percepção de Qualidade em jornais de Santa Catarina inclui a categoria "Qualidade dos Bancos de Dados", mas o texto não esclarece exatamente o que está sendo medido sob essa rubrica. Ziller (2005), utilizando um referencial semiótico, reforça a idéia da inexistência de critérios consensuais para aferição de Qualidade e ressalta o lugar da multimidialidade como fator diferencial de Qualidade para publicações jornalísticas online, porém, mais uma vez, a dimensão da Memória está ausente.

A percepção de que modelos especificamente desenvolvidos para análise de produtos jornalísticos na Web eram necessários, bem como de que a Memória funcionava como elemento de agregação de valor ao material jornalístico e deveria ser incluída como um indicador de Qualidade já estava presente - ainda que incipientemente - em um estudo levado a cabo pelo GJOL (Grupo de Pesquisa em Jornalismo Online) da Universidade Federal da Bahia, em 2002, quando o quesito Memória (existência de Arquivos) foi incluído dentre os elementos pesquisados, em um trabalho de levantamento e mapeamento das características então identificáveis em jornais online brasileiros e portugueses (Mielniczuk et alii, 2002). A mesma preocupação vai se evidenciar no estudo de Machado et alii (2003) sobre padrões do jornalismo online na Bahia.

Persiste, no entanto, a dificuldade de se poder utilizar um modelo já testado e direcionado para avaliação qualitativa de sites de produção jornalística especificamente. Em estudo realizado em 2004, Hope \& Li, usando uma classificação de Zhang \& Dran (2000) propuseram uma lista de fatores identificáveis em um Website em dois grupos: Fatores de Higiene (Hygiene Factors) e Fatores Motivadores (Motivator Factors). Fatores de Higiene são os elementos cuja presença no Website é funcional e de serviço e cuja ausência causa insatisfação; Fatores de Motivação são aqueles que agregam valor a um Website e contribuem para a satisfação do usuário. A referência à Memória como Fator Motivador apareceu sob a rubrica geral Archives (Arquivos), recebendo pontuação relativamente baixa na percepção dos participantes do teste quanto à sua importância no conjunto de fatores propostos para a aferição de Qualidade.

\section{Experiência recente e indicações}

No âmbito do Convênio de Colaboração Brasil-Espanha para o estudo dos Cibermeios (CAPES/DGU 140/07), como primeiro passo em um processo de estabelecimento de metodologia comparativa para análise de produtos Ciberjornalístcos optou-se, em função da escassez de modelos prontos aplicáveis e da existência de uma utilização anterior pelo grupo de pesquisadores espanhóis participantes do Convênio, pela adoção do modelo de 
Lluis Codina (2003) para avaliação de produtos online. A escolha do questionário Codina foi realizada com plena consciência prévia das limitações do modelo, e com vistas à sua utilização crítica e sujeita a modificações e ampliações.

A limitação maior se deve justamente ao fato de que o modelo Codina, como tantos outros, está direcionado para análise de sites em geral, e não especificamente para a avaliação qualitativa de sites jornalísticos em particular.

Ademais, como assinala Saad (2008), persiste sem solução em Codina o problema da subjetividade inerente a tal tipo de estudo. Codina simplesmente coloca a subjetividade e a intrasubjetividade como dados do processo que devem ser aceitos. Assim, respondendo à pergunta como combater a subjetividade, diz:

O primeiro a se assinalar é que não se pode eliminá-la de todo, no entanto, pode-se fazer algumas coisas para reduzi-la ao máximo ou para rebaixá-la a um nível localizado (anedótico). Um método é a experiência e outro a intersubjetividade. Comecemos com o segundo: diversos estudos de usabilidade (...) se resolvem com a realização do mesmo estudo por três pessoas diferentes (...) O método da experiência nos indica que é aconselhável que os avaliadores tenham um bom conhecimento do tema (...) uma terceira opção pode consistir, simplesmente, em retirar aqueles indicadores que se considerem excessivamente subjetivos, se o contexto do tipo de avaliação o permite (Codina, 2003, p. 166). ${ }^{8}$

O modelo de questionário de Codina foi trabalhado pelo grupo de pesquisadores do Brasil e Espanha, no sentido de uma adaptação que buscava - sem descaracterizá-lo em suas linhas mestras - aproximá-lo das especificidades a serem avaliadas em sites jornalísticos.

Um questionário redesenhado a partir do original, através da análise crítica dos participantes do Grupo foi gerado e um piloto aplicado a uma publicação online (jornal Público, de Portugal), em 15 de maio de 2008. A partir do piloto, uma segunda versão foi produzida para aplicação em sete jornais brasileiros e sete jornais espanhóis, em 10 de setembro de $2008^{9}$. A aplicação do questionário aos 14 veículos ocorreu em dois horários préfixados (9:00 horas e 20:00 horas dos respectivos horários locais do Brasil e Espanha), com o objetivo de incluir entre os propósitos da avaliação as variações detectáveis entre as edições analisadas nos dois diferentes momentos. As primeiras análises e reflexões decorrentes da aplicação do questionário Codina modificado tendem a indicar que ele pode ser útil para identificar, em linhas gerais, o "estado do site" de cada jornal, no que diz respeito àquilo que mais acima denominamos formas "consensuais" ou "intersubjetivas" mais genéricas de mensuração, ou seja, torna-se possível estabelecer a posição relativa de cada diário, quando comparada ao conjunto avaliado, no que diz respeito àqueles indicadores de caráter mais universal e genérico, aplicáveis a qualquer tipo de site.
Ressalte-se, preliminarmente, que isso não representa pouco, uma vez que possibilita o estabelecimento de um conjunto de critérios de comparação entre veículos, além de poder funcionar como um instrumento útil para o estabelecimento de mapeamentos e de avaliações preliminares, bem como para a detecção prévia dos problemas mais evidentes, em fases iniciais de uma consultoria mais especializada a ser oferecida a um determinado veículo.

É, no entanto, quando nos debruçamos sobre o que podemos denominar as especificidades dos sites jornalísticos que os limites do instrumento Codina se tornam patentes. Ou seja, apesar de detectar aspectos da estruturação do site e da própria estruturação dos conteúdos, que são de central interesse para a análise de produtos Ciberjornalísticos, na medida em que possibilita uma aproximação às características associadas à escrita jornalística na Web (Hipertextualidade, Multimidialidade, Interatividade, Costumização/Personalização, Atualização, Memória $)^{10}$, o instrumental de Codina mostra-se limitado ao não possibilitar a análise das formas específicas que tais elementos assumem no texto Ciberjornalístico tomado em sua dimensão histórica.

Explicando melhor: quando se fala em tais características (Hipertextualidade, Multimidialidade, Interatividade, Costumização/Personalização, Atualização, Memória) em sua operacionalização no texto jornalístico produzido para a Internet estamos falando de algo dinâmico, que vem atravessando diversas fases de desenvolvimento, desde o puramente transpositivo, até emergentes "formas próprias" (novos gêneros?) já detectáveis em alguns produtos de alguns veículos jornalísticos, especialmente como efeito do uso alargado e potencializado das bases de dados como elemento estruturante do formato jornalístico online (Barbosa, 2008a e 2008b; Fidalgo, 2004; Machado, 2004).

Para exemplificar o problema que estou levantando, tomemos uma das características sob análise, qual seja a memória, e examinemos qual é seu tratamento analítico através da ferramenta/questionário proposta por Codina.

No formulário Codina original (2003) a Memória aparece sob a rubrica Arquivos, sendo analisada de maneira binária:

1. Possibilidade de Consulta a exemplares atrasados (Sim ou Não)

\section{Existência de Hemeroteca Histórica ( Sim ou Não)}

Em caso positivo: Acesso Livre ou Acesso Pago

Em caso de Acesso Livre: Necessidade ou Não de Registro do Usuário

Como se verifica, a concepção subjacente é de um Arquivo estático, que pode apenas ser consultado, não havendo abertura para uma análise de uma utilização dinâmica e integrada dos recursos de Memória, ou seja, não está em pauta uma análise dos textos produzidos e 
o uso da Memória (Bases de dados) na construção da informação jornalística (narratividade). Após aplicação do piloto, no âmbito do Convênio Brasil-Espanha, uma reformulação foi proposta, no sentido de se incorporar também uma verificação - ainda que sumária - de existência de Memória integrada/dinâmica, com a inclusão de um quesito sobre uso efetivo do arquivo nos textos produzidos:

Itens de Arquivo se incorporam como conteúdo relacionado às notícias disponíveis no veículo analisado? (Sim ou Não)

Trata-se de um passo inicial, que possibilita um melhor enquadramento da Memória enquanto critério de avaliação de Qualidade, mas que, certamente, ainda está longe de dar conta de todos os aspectos relacionados a "formas específicas" de utilização da Memória no texto jornalístico (Canavilhas, 2004; Palacios, 2004; David, 2004; Mielniczuk \&. Barbosa, 2005; Ribas, 2008), especialmente no que diz respeito à sua função de elemento essencial de criação de Contexto.

Limitações de cunho semelhante podem ser observadas com respeito às demais características usualmente associadas ao texto jornalístico na Web (Hipertextualidade, Multimidialidade, Interatividade, Customização/ Personalização, Atualização). Para cada um de tais itens, coloca-se a tarefa inescapável e o desafio de estabelecimento de indicadores específicos mais amplos e detalhados, que possam traduzir de forma mais apropriada os níveis de sua incorporação e efetiva utilização na produção de um texto jornalístico. As dificuldades de tal empreendimento são detectáveis até mesmo pelo caráter vago - temos plena consciência disso - de alguns dos termos que estamos utilizando neste artigo, como "amplos" ou "apropriados", que, obviamente, requerem maior explicitação e elaboração. E tal elaboração somente se pode dar através da construção experimental de novos instrumentos, em sucessivas aproximações e refinamentos conceituais e pragmáticos.

Se nos mantivermos nos limites de nossa definição geral e mínima de Qualidade, apresentada no início deste artigo ("A Qualidade é o conjunto de propriedades e características de um produto ou serviço que lhe confere sua aptidão para satisfazer necessidades expressas ou implícitas"), parece inevitável que o avanço da "alfabetização digital" dos usuários da Web reclame ("expressa ou implicitamente") do produto jornalístico disponibilizado um grau de sofisticação cada vez maior no que diz respeito às formas específicas de colocar em uso as possibilidades e potencialidades abertas pela nova plataforma de produção.

\section{Inconclusões e recorrências}

Intitulado como Apontamentos, este breve artigo não pode ter pretensões de conclusões, no sentido estrito do termo. Assinalaremos, tão somente, alguns elementos recorrentes, que devem figurar em reflexões futuras sobre a inclusão do item Memória na aferição de Qualida- de dos jornais produzidos em redes telemáticas.

É bastante claro que as crescentes possibilidades abertas para a recuperação de Memória, a partir da sofisticação das bases de dados na produção jornalísticas, têm efeitos que podem e devem ser avaliados:

a) Nas rotinas produtivas nas Redações, com a crescente facilidade de consultas e apropriação de informações em bases de dados internas e externas ao veículo;

b) Nos modelos de negócios, com uma vasta gama de possíveis incorporações de elementos de Memória como parte do negócio estabelecido para os jornais (acesso pago total ou parcial; conjugação de Bases de Dados/ Memória/Publicidade; outras formas de agregação de valor);

c) Na produção de formatos narrativos diferenciados, com distintas formas de incorporação de Memória (background, contexto, contraposição, etc);

d) Nas formas de interação com o Usuário, que passa a dispor de recursos para investigar, no próprio site do jornal, aspectos históricos em torno do material de Atualidade que lhe é oferecido, bem como, eventualmente, personalizar sua Memória em espaços do próprio site jornalístico que utiliza.

Das ilações acima decorre, como apontamentos para futuras investidas na criação de elenco de características a serem investigadas em estudos de levantamento e rankeamento de Qualidade em produtos jornalísticos:

a) a necessidade de superação da evidente pouca atenção que o item vem recebendo nos estudos até aqui realizados, tanto no âmbito nacional quanto internacional;

b) a necessidade de alargamento da concepção de Memória, uma vez que, nos casos em que há algum tipo de inclusão desse item na listagem de critérios utilizados, fica a apreciação restrita à dimensão do "Arquivo" (existência ou não; acesso livre ou pago; extensão temporal do material disponibilizado, etc);

c) a necessidade de proposição de desdobramentos para a questão da efetiva incorporação de elementos de Memória na estruturação dos textos jornalísticos em futuras avaliações de Qualidade de produtos, inclusive quanto às formas de ocorrência e seus efeitos sobre a narratividade;

d) a necessidade de se atentar para as possibilidades de Personalização de Memória, com a criação pelos jornais de áreas de leitores, onde possibilidades de clipagem e hiperlinkagem personalizadas venham a constituir novas formas de utilização de Memória e, portanto, de agregação de valor ao material jornalístico originalmente produzido. 
Apesar da evidente dificuldade de operacionalização de tais dimensões de apropriação sócio-técnica da Memória nos questionários de observação de conteúdos, utilizados na avaliação de corpora de larga escala (como é o caso do modelo proposto por Codina), é preciso buscar-se a máxima viabilização de aferições desse item já no estágio de mapeamento, representado pela aplicação dos questionários, para que, em etapa posterior, refinamentos possam ser operacionalizados em abordagens mais qualitativas, in loco, e para corpora mais reduzidas mFAmEcos

\section{NOTAS}

* Este texto foi apresentado no II Simpósio Nacional da ABCiber realizado em novembro de 2008.

1 As reflexões desenvolvidas neste artigo têm como ponto de apoio resultados - ainda bastante preliminares e pouco sistematizados - de uma pesquisa em curso no âmbito do Convênio de Colaboração BrasilEspanha para o estudo dos Cibermeios (CAPES/ DGU 140/07). Envolvendo sete universidades brasileiras e sete universidades espanholas, a investigação tem como objetivo central estabelecer uma comparação entre os padrões de webjornalismo no Brasil e na Espanha, devendo estender-se até 2010. Uma versão preliminar deste artigo foi apresentada no II Colóquio da ABCiber, Associação Brasileira de Pesquisadores em Cibercultura, PUC-SP. Novembro de 2008.

2 Pulitzer Prize Site, FAQs, http: www.pulitzer.org/ faq. Acesso em 27/07/2008

3 " 1 . Independence; financial stability; integrity; social concern; good writing and editing. 2. Strong opinion and interpretive emphasis; world consciousness; non sensationalism in articles and makeup.3. Emphasis on politics, international relations, economics, social welfare, cultural endeavors, education, and science.4. Concern with getting, developing and keeping a large, intelligent, well educated, articulate and technically proficient staff. 5 . Determination to serve and help expand a well educated, intellectual readership at home and abroad; desire to appeal to, and influence, opinion leaders everywhere" (MERRIL, 1968).

4 O Newspaper Readership Project foi criado Conjuntamente pela American Newspaper Publishers Association e Newspaper Advertising Bureau. Leo Bogart foi seu vice-presidente-executivo entre 1977 a 1983. O projeto estava direcionado para investigar as razões da queda de circulação dos jornais norteamericanos.
5 Bogart (2004) cita Lord Kelvin ("grande físico e cientista vitoriano") criador da escala de temperatura que leva seu nome, afirmando que "quando você pode medir aquilo sobre o que está falando e expressá-lo em números, você sabe algo sobre o objeto; quando você não pode medir, não pode expressar em números, seu conhecimento é de uma natureza débil (meager) e insatisfatória".

6 "High ratio of news interpretations and backgrounders to spot news report".

7 Veja-se o sumário de referências sobre análise de sites em geral em Hope \& Li (2004).

8 Lo primero que hay que señalar es que no se puede eliminar del todo, sin embargo se pueden hacer algunas cosas para reducirla al máximo o para rebajarla a un nivel anecdótico. Un método es la experiencia y otro la intersubjectividad. Empecemos por el segundo, diversos estudios de usabilidad [...] se resuelven com la realización del mismo estudio por tres personas distintas [...] El Método de la experiencia nos indica que es aconsejable que los evaluadores tengan un buen conocimiento del tema [...] una tercera opción puede consistir, simplemente, en retirar aquellos indicadores que se consideren excesivamente subjetivos si el contexto del tipo de evaluación lo permite (Codina, 2003, p. 166).

9 São os seguintes os jornais incluídos na avaliação, pelo lado brasileiro: Folha de São Paulo (São Paulo), Diário de Santa Catarina (Florianópolis), Gazeta do Povo (Curitiba), Jornal do Comércio (Recife), Zero Hora (Porto Alegre), A Tarde (Salvador) e O Correio Brasiliense (Brasília). Pela parte espanhola temos: Sur (Andalucia), El Correo (Bilbao), Diario de Navarra, La Vanguardia, La Voz de Galicia, Las Provincias o Levante (Valencia), El Mundo e El País.

10 Para uma aproximação inicial aos estudos que se debruçam sobre aspectos da caracterização do texto jornalístico na Web e suas fases ou etapas de desenvolvimento, a partir da ótica de uma vasta gama de autores, recomendamos como um possível ponto de partida a já considerável produção dos integrantes do GJOL (Grupode Pesquisa em Jornalismo Online), disponível em <http://www.facom.ufba.br/jol .

\section{REFERÊNCIAS}

BARBOSA, Suzana. Jornalismo Digital em Ambientes Dinâmicos. Propriedades, rupturas e potencialidades do Modelo JDBD. In: Observatorio (OBS*) Journal, 4 (2008a), 217-244. Disponível em: <http:// obs.obercom.pt>. Acesso 18/07/2008.

. Modelo JDBD e o ciberjornalismo de quarta geração. 
Artigo apresentado no III Congreso Internacional de Periodismo en la Red - Foro Web 2.0: Blogs, Wikis, Redes Sociales y e-Participación, GT 7 - Cibercultura y Tendencias de la Prensa en Internet. Facultad de Ciencias de la Información, Universidad Complutense de Madrid, (2008b).

Identificando remediações e rupturas no uso de bancos de dados no jornalismo digital. In: Anais do II SBPJor. Salvador-BA/Brasil, 2004.

BOGART, L. Press and Public: Who Reads What, When, Where, and Why in American Newspapers (2nded.). Hillsdale, NJ: Lawrence Erlbaum and Associates, Inc. 1989.

Reflections on Content Quality in Newspapers. Newspaper Research Journal, Winter, 2004. Disponível em Bnet Business Network, <http:/ / findarticles.com/ p/articles/mi_qa3677/is_200401/ai_n9353031/>. Acesso em 27/07/2008.

CANAVILHAS, João. A Internet como Memória, UBI/ BOCC, 2004. Disponível em: <http:// www.bocc.ubi.pt/pag/canavilhas-joao-internetcomo-memoria.pdf>. Acesso em 25/07/2008.

CARRATO, Angela. Jornal online, uma avaliação sobre a experiência mineira, Intercom 2001, disponível em: <http:/ / reposcom.portcom.intercom.org.br/dspace/ bitstream/1904/4350/1/NP2CARRATO.pdf >. Acesso em 25/07/2008.

CODINA, Lluis. Hiperdocumentos: composición, estructura y evaluación. In: NOCI, Javier Dias e SALAVERRÍA, Ramon (orgs.) Manual de Redacción Ciberperiodistica, Barcelona: Ed. Ariel, 2003.

DAVID, Monica. Conexões de Memória: os testemunhos, os dados e o jornalismo online, in: Congresso IberoAmericano de Periodismo em Internet, Salvador, 2004. Disponívelem: <http://www.espacioblog.com/myfiles/ciberperiodismo/AIAPI\%202004\%20Monica\%20David.pdf>. Acesso em 28/07/2008.

FIDALGO, António. Do poliedro à esfera: os campos de classificação. A resolução semântica no jornalismo online. In: Anais do II SBPJor. Salvador-BA/Brasil, 2004.

GALARÇA, Sandro. Jornalismo online: como os internautas catarinenses avaliam duas propostas diferentes na Internet. Anais. São Paulo: Intercom, 2005. CD-ROM, Disponível em : < http:// reposcom.portcom.intercom.org.br/dspace/bitstream/1904/17827/1/R1529-1.pdf>. Acesso em 28/ $07 / 2008$.
GEORGIASCHOLASTICPRESS ASSOCIATION. Newspaper evaluation guidebook, Henry W. Grady School of Journalism disponívelem:<http://www.grady.uga.edu/ gspa/Forms/WEBNewspaper.pdf>. Acesso em 28/07/ 2008.

GLADNEY, G. A. Newspaper Excellence: How Editors of Small and Large Papers Judge Quality. Newspaper Research Journal, 11(2), 58-71, 1990.

HOBSBAWN, Eric. The age of revolution, 1789/1898. Wendenfeld \& Nicolson, London, 1962.

HOPE, B. \& LI, Z. Online newspapers: the impact of culture, sex, and age on the perceived importance of specified quality factors. In: Information Research, Vol. 9 No. 4, July 2004. Disponível em: <http:/ /informationr.net/ ir/9-4/paper197.html\#Zhang\#Zhang>. Acesso em 25/07/2008.

JIMÉMEZ, Marina Piano \& ORTIZ REPISO, Virgínia. Evaluación y calidad de sedes web. Ediciones Trea, Gijón, 2007.

LACY, S., \& FICO, F. Newspaper Quality and Ownership: Rating the Groups. Newspaper Research Journal, 11(2), 42-56, 1990.

MACHADO, Elias. O jornal digital como epicentro das redes de circulação de notícias, 2001. Disponível em: <http:/ / reposcom.portcom.intercom.org.br/bitstream/1904/4369/1/NP2MACHADO.pdf >. Acesso 20/07/2008.

Banco de dados como formato no jornalismo digital. In: Anais VI Lusocom, (CD-ROM), Covilhã, Portugal, abril, 2004a.

MACHADO, Elias, BORGES, Clarissa e MIRANDA, Milena. Modelos de produção de conteúdo no jornalismo digital baiano. In: MACHADO, Elias \& PALÁCIOS, Marcos (org.). Modelos de jornalismo digital. Salvador, Calandra, 2003.

McADAMS, Melinda. Inventing an online newspaper. In: Interpersonal Computing and Technology: An Electronic Journal for the 21st Century, July, 1995, Volume 3, Number 3, pp. 64-90. Disponível em: <http:// www.helsinki.fi/science/optek/1995/n3/ mcadams.txt>. Acesso em 25/07/2008.

MERRIL, J. C. The Elite Press: Great Newspapers of the World. New York: Pitman Publishing Corp. 1968.

MERRIL, J. C., \& LOWENSTEIN, R. L. Media, Messages and Men: New perspectives in Communications. New 
York: David Mckay \& Company, Inc., 1971

MEYER, Philip \& KIM, Koang-Hyub. Quantifying Newspaper Quality: "I know it when I see it", paper delivered to the Newspaper Division, Association for Education in Journalism and Mass Communication, Kansas City, Mo., July 3, 2003.

MIELNICZUK, Luciana. BARBOSA, Suzana. Digital Journalism. Democratizing Social Memory. In: Brazilian Journalism Research, Vol.1, n. 2, semester 2, 2005. Disponível em: <http://www.unb.br/ojsdpp/ viewissue.php?id=2 >. Acesso em 23/07/2008.

. MIELNICZUK, L.; BARBOSA, S.; RIBAS, B.; NARITA, S. , PALACIOS, M. Um mapeamento de características e tendências no jornalismo online brasileiro e português. In: Comunicarte, Revista de Comunicação e Arte, vol.1, n.2, Universidade de Aveiro, Portugal, set.2002.

NIELSEN, J. Designing Web usability: the practice of simplicity. Indianapolis, In: New Riders, 1999.

Ten usability heuristics. Disponível em: <http:// www.useit.com/papers/heuristic/heuristic_listhtml>.Acesso em 29/07/2008.

NIELSEN, J.\& TAHIR, M. Homepage usability: 55 Websites deconstructed. Indianapolis, In: New Riders, 2001.

PALACIOS, Marcos. Ruptura, Continuidade e Potencialização no Jornalismo Online: o Lugar da Memória. In: MACHADO, Elias; PALACIOS, Marcos (orgs), Modelos do Jornalismo Digital. Salvador: Calandra, 2004. Disponível em:

<http://www.facom.ufba.br/jol/pdf/ 2003_palacios_olugardamemoria.pdf $>$. Acesso em $28 / 07 / 2008$.

PALACIOS, M. et al. Um Jornal Laboratório multimídia, multi-usuário e descentralizado. O caso da Plataforma Panopticon. In: Pauta Geral, Ano 12, No 7. Salvador: Calandra. pp: 105-115, 2005.

RIBAS, Beatriz. Memória e ciberjornalismo: considerações sobre potencialidades para a reconfiguração da prática jornalística nas redes digitais, texto submetido como requisito parcial para a Qualificação Doutoral, Programa de Pós-Graduação em Comunicação e Cultura Contemporâneas, FACOM/UFBA, Salvador, 2008.

SAAD, Elizabeth Corrêa. Relatório integrador do testepiloto da ficha de avaliação de qualidade dos ciber- meios. Equipe brasileira do Convênio Capes-DGU, Documento Interno do Convênio CAPES/DGU 140/ 07, 2008.

SILVA JÚNIOR, Afonso da. Uma Trajetória em Redes: Modelos e Características Operacionais das Agências de Notícias, das Origens às Redes Digitais, com Três Estudos de Caso. (Tese de Doutorado). FACOM/ UFBA, Salvador, 2006. Disponível em: <http:// www.facom.ufba.br/jol/producao_teses $>$. Acesso em: 20/07/2008.

STONE, G. C., STONE, D. B., \& TROTTER, E. P. (1981).Newspaper Quality's Relation to Circulation. Newspaper Research Journal, 2(3), 16-24, 1981.

ZHANG, P. \& DRAN, G.M. Satisfiers and dissatisfiers: a two-factor model for Website design and evaluation. Journal of the American Society for Information Science, 51(14), 1253-1268, 2000.

ZILLER, Joana. A qualidade de informação em webjornais - conceitos norteadores. XXVIII Congresso Brasileiro de Ciências da Comunicação - Uerj - 5 a 9 de setembro de 2005, disponível em< http:// reposcom.portcom.intercom.org.br/dspace/bitstream/1904/16804/1/R1699-1.pdf>. Acesso em 29/ $07 / 2008$. 